\title{
Gastro-oesophageal reflux in infants under 6 months with cystic fibrosis
} Ralf G Heine, Brenda M Button, Anthony Olinsky, Peter D Phelan,
Anthony G Catto-Smith
Royal Children's Hospital, Melbourne, Australia:

Department of Gastroenterology R G Heine

A G Catto-Smith

Department of Physiotherapy B M Button

Department of Thoracic Medicine A Olinsky

P D Phelan

Correspondence to: Dr A G Catto-Smith, Department of Gastroenterology, Royal Children's Hospital,

Flemington Road, Parkville, Victoria 3052, Australia. e-mail: cattosmt@cryptic. rch.unimelb.edu.au

Accepted 22 August 1997

\begin{abstract}
Aim-To establish the incidence of pathological gastro-oesophageal reflux (GOR) in newly diagnosed infants with cystic fibrosis and to identify clinical predictors of increased reflux.

Methods-26 infants with cystic fibrosis less than 6 months of age (14 male, 12 female; mean (SEM) age 2.1 (0.21) months, range 0.8 to 5.6 months) underwent prolonged oesophageal $\mathrm{pH}$ monitoring (mean duration 27.1 (0.49) hours; range 21.3 to 30.2 hours). Reflux symptoms, anthropometric variables, pancreatic status, meconium ileus, genotype, and chest $x$ ray findings were correlated with pH monitoring data.

Results-Five infants $(19.2 \%)$ had an abnormal fractional reflux time of greater than $10 \%$, seven $(26.9 \%)$ of $5-10 \%$, and 14 $(53.8 \%)$ of below $5 \%$. Infants who presented with frequent vomiting had a significantly higher fractional reflux time than infants who had infrequent or no vomiting. There was no significant association between abnormal chest $x$ rays and pathological GOR. Sex, genotype, nutritional status, meconium ileus, and pancreatic enzyme supplementation were not significantly associated with pathological GOR.

Conclusions-About one in five newly diagnosed infants with cystic fibrosis had pathological GOR. Pathologically increased reflux was present before radiological lung disease was established. Apart from frequent vomiting, no useful clinical predictors of pathological reflux were found.

(Arch Dis Child 1998;78:44-48)
\end{abstract}

Keywords: gastro-oesophageal reflux; cystic fibrosis

The prognosis of cystic fibrosis has changed dramatically over the past decades. Rigorous antibiotic treatment of chest infections, pancreatic enzyme replacement, and chest physiotherapy have become mainstays of current treatment regimens. ${ }^{1}$ Since the introduction of newborn screening for cystic fibrosis in the state of Victoria in 1989, infants carrying the $\Delta \mathrm{F}_{508}$ mutation are diagnosed at about 6 weeks of age. ${ }^{2}$ Identification of these mostly presymptomatic infants has made early treatment possible and this may ultimately improve long term survival. ${ }^{3}$

Children with cystic fibrosis have a high incidence of pathologically increased gastro- oesophageal reflux (GOR). ${ }^{4-10}$ Reported complications include reflux oesophagitis ${ }^{11}$ and peptic strictures. ${ }^{12}$ In view of the improved long term survival, other potential complications may need to be considered, including Barrett's metaplasia ${ }^{13}$ and, potentially, adenocarcinoma of the oesophagus. ${ }^{14}$ In infants, persistent vomiting and regurgitation of food can compound poor weight gain and nutritional deficiencies. Chest physiotherapy in postural drainage positions may exacerbate GOR in infants with cystic fibrosis. ${ }^{15}$ Recent studies also suggest that GOR may adversely affect lung disease by aspiration and reflex bronchospasm. ${ }^{16}{ }^{17}$

It has not been clear whether increased reflux occurs before or after development of lung disease. No reliable figures on the incidence of GOR in infants with cystic fibrosis are available. Different normal values for reflux indices apply in infancy, ${ }^{18}$ which makes comparison between studies difficult. Incidence figures in older children vary between $25 \%$ and $100 \%$, depending on patient selection. ${ }^{46710}$ The aim of our study was to establish the incidence of pathological GOR in newly diagnosed infants with cystic fibrosis and to identify clinical predictors of reflux in these patients.

\section{Methods}

Forty one infants with cystic fibrosis were diagnosed in Victoria between February 1993 and March 1995. The families of five infants were not included in the study, and the study was interrupted for four months from April to July 1994. Of the remaining 36 infants, 26 $(72.2 \%)$ were enrolled in the study, 10 families declining to participate. All infants were under 6 months of age at the time of enrolment (14 male, 12 female; mean (SEM) age $2.1(0.21)$ months, range 0.8 to 5.6 months). The diagnosis of cystic fibrosis was made if infants were homozygous for the $\Delta \mathrm{F}_{508}$ mutation ( $\mathrm{n}=$ 16). In infants with other genotypes the diagnosis was confirmed by abnormal sweat pilocarpine iontophoresis (sweat chloride $>60$ $\mathrm{mmol} / \mathrm{l}){ }^{19}$

The project was approved by the Royal Children's Hospital ethics in human research committee.

CLINICAL PRESENTATION AND SYMPTOMS OF GOR A detailed history was taken from the parents, with particular reference to initial presentation, feeding details, nutritional supplementation, and use of pancreatic enzymes. A brief questionnaire on symptoms of GOR was administered before $\mathrm{pH}$ monitoring. This included questions about frequency of 
Table 1 Reflux data

\begin{tabular}{|c|c|c|c|c|c|c|c|}
\hline & No & $\begin{array}{l}\text { No of reflux } \\
\text { episodes per } 24 h\end{array}$ & $p$ Value & $\begin{array}{l}\text { Mean duration of } \\
\text { reflux episodes (min) }\end{array}$ & $p$ Value & $\begin{array}{l}\text { Mean fractional } \\
\text { reflux time (\%) }\end{array}$ & $p$ Value \\
\hline Total & 26 & $25.9(2.7)$ & - & $3.6(0.6)$ & - & $5.7(0.8)$ & - \\
\hline Frequent regurgitation & 12 & $28.7(4.2)$ & & $4.1(0.7)$ & & $7.6(1.2)$ & \\
\hline Infrequent/no regurgitation & 14 & $23.6(3.4)$ & 0.36 & $2.7(0.4)$ & 0.11 & $4.1(0.7)$ & 0.03 \\
\hline \multicolumn{8}{|l|}{ Irritability } \\
\hline Yes & 7 & $28.1(4.2)$ & & $3.5(0.6)$ & & $7.3(1.8)$ & \\
\hline No & 19 & $25.1(3.3)$ & 0.58 & $3.3(0.5)$ & 0.80 & $5.1(0.8)$ & 0.29 \\
\hline Breast fed & 20 & $26.9(3.0)$ & & $3.2(0.3)$ & & $5.9(0.9)$ & \\
\hline Bottle fed & 6 & $22.7(6.0)$ & 0.55 & $3.8(1.5)$ & 0.67 & $4.9(1.2)$ & 0.49 \\
\hline FTT & 8 & $22.3(5.5)$ & & $3.1(0.7)$ & & $5.0(1.7)$ & \\
\hline No FTT & 18 & $27.6(3.0)$ & 0.61 & $3.4(0.5)$ & 0.72 & $6.0(0.8)$ & 0.61 \\
\hline \multicolumn{8}{|l|}{ Meconium ileus or ileal atresia } \\
\hline Yes & 6 & $34.7(5.3)$ & & $3.2(0.5)$ & & $7.8(1.7)$ & \\
\hline No & 20 & $23.3(2.9)$ & 0.10 & $3.4(0.5)$ & 0.80 & $5.0(0.8)$ & 0.18 \\
\hline Pancreatic sufficient & 4 & $23.6(3.4)$ & & $2.9(1.0)$ & & $4.2(1.9)$ & \\
\hline Pancreatic insufficient & 22 & $28.7(4.2)$ & 0.45 & $3.4(0.5)$ & 0.64 & $6.0(0.8)$ & 0.44 \\
\hline \multicolumn{8}{|l|}{ Genotype } \\
\hline Homozygous for $\Delta \mathrm{F}_{508}$ & 16 & $26.1(3.3)$ & & $3.7(0.6)$ & & $5.9(0.9)$ & \\
\hline Heterozygous for $\Delta \mathrm{F}_{508}$ & 7 & $23.5(5.4)$ & 0.69 & $2.2(0.4)$ & 0.05 & $4.0(1.6)$ & 0.32 \\
\hline \multicolumn{8}{|l|}{ Chest $x$ ray } \\
\hline Normal & 15 & $27.6(3.6)$ & & $3.6(0.7)$ & & $6.9(1.2)$ & \\
\hline Abnormal & 11 & $23.7(4.0)$ & 0.47 & $2.9(0.4)$ & 0.31 & $4.1(0.5)$ & 0.04 \\
\hline
\end{tabular}

Values are mean (SEM); FTT = failure to thrive.

vomiting/regurgitation, haematemesis, cyanotic episodes, apnoea, and distressed behaviour.

FEEDING DETAILS AND NUTRITIONAL ASSESSMENT Body weight and length were measured at birth and at the time of $\mathrm{pH}$ monitoring; $\mathrm{z}$ scores for weight for age and weight for length for age were then calculated using an anthropometric software program (Epi Info 5.01, Centers for Disease Control, Atlanta, USA). Failure to thrive was defined as a $\mathrm{z}$ score for weight for age or weight for length for age of below -2 at the time of $\mathrm{pH}$ monitoring, or a fall in one of these $z$ scores of greater than 2 SD between birth and $\mathrm{pH}$ monitoring.

\section{ASSESSMENT OF PANCREATIC STATUS}

Faecal microscopy was routinely performed in all patients. Pancreatic insufficiency was diagnosed on the basis of gross steatorrhoea and absence of faecal tryptic activity. Four patients had 72 hour faecal fat collections. Patients who presented with meconium ileus were considered to have pancreatic insufficiency. The use of pancreatic enzyme replacement was documented.

OESOPHAGEAL 24 HOUR PH MONITORING Prolonged oesophageal $\mathrm{pH}$ monitoring was routinely performed in all 26 patients regardless of symptoms of GOR. Oesophageal pH monitoring was performed by an experienced gastroenterology technician using a Digitrapper (Synectics Medical, Sweden) with an antimony electrode. None of the infants were taking antireflux medications. The $\mathrm{pH}$ probe was calibrated using two standardised buffer solutions $(\mathrm{pH} 1.04$ and $\mathrm{pH} 7.0$ ), inserted through the nose and positioned in the lower oesophagus. The exact position was determined by use of a height based formula, ${ }^{20}$ and by retraction of the probe from the stomach after an acidic reading had been obtained. Infants were breast fed or received their usual formula during the study period and were not offered acidic drinks. A diary with information on feeding time and posture was kept for 24 hours. Data were analysed with help of a PC software program (EsopHogram, Gastrosoft, Texas, USA). Periods of chest physiotherapy were excluded from analysis, as GOR may be increased during postural drainage chest physiotherapy. ${ }^{15} \mathrm{~A}$ fractional reflux time of greater than $10 \%$ with an oesophageal $\mathrm{pH}$ of below 4.0 was considered pathological. ${ }^{18}$

\section{CHEST RADIOGRAPHY}

Chest radiographs were taken within two weeks of $\mathrm{pH}$ monitoring and assessed by an experienced paediatric radiologist. Radiographs were reported as either normal or as showing focal or diffuse abnormalities.

STATISTICAL ANALYSIS

Data were analysed by calculation of means (quoted as mean (SEM)), by one sample or paired $t$ test and by $\chi^{2}$ test. Results were considered statistically significant if they reached the 95\% level $(p<0.05)$. Analyses were performed using the PC software packages MS-Excel 5.0 for Windows and Minitab 10.1 for Windows.

\section{Results}

OESOPHAGEAL pH MONITORING RESULTS

The mean duration of $\mathrm{pH}$ recordings was 27.1 (0.49) hours (range 21.3 to 30.2 hours). Five of the 26 infants $(19.2 \%)$ had an abnormal fractional reflux time of more than $10 \%{ }^{20}$; seven $(26.9 \%)$ had a value of between $5 \%$ and $10 \%$, and $14(53.8 \%)$ had a value below $5 \%$.

\section{CLINICAL PRESENTATION AND GOR}

Parents of 12 infants (46.2\%) gave a history of frequent vomiting or posseting after most feeds. The remaining infants had infrequent (n $=9$ ) or no vomiting $(n=5)$. Infants with frequent vomiting had a significantly higher fractional reflux time than infants with infrequent or absent vomiting $(p=0.03)$. Four of the 12 infants with frequent vomiting or posseting had pathological reflux. The positive predictive value of frequent vomiting/posseting for pathological GOR was only $33.3 \%$, and the $\chi^{2}$ test was not significant $(4 / 12 v 1 / 13, \mathrm{p}=$ 
Table 2 Genotype data

\begin{tabular}{lrr}
\hline Genotype & No (\%) \\
\hline Homozygous $\Delta \mathrm{F}_{508} / \Delta \mathrm{F}_{508}$ & & $16(61.5)$ \\
Compound heterozygous & 2 & \\
$\Delta \mathrm{F}_{508} / \mathrm{G} 551 \mathrm{D}$ & 2 & \\
$\Delta \mathrm{F}_{508} / 1717-1 \mathrm{G} \rightarrow \mathrm{A}$ & 1 & \\
$\Delta \mathrm{F}_{508} / 621+1 \mathrm{G} \rightarrow \mathrm{T}$ & 2 & \\
$\Delta \mathrm{F}_{508} /$ unidentified & 1 & \\
Other & 1 & \\
G542X/N1303K & 1 & \\
N1303K/N1303K & & $26(11.5)$ \\
Unidentified & & \\
Total & & \\
\hline
\end{tabular}

0.09). However, the negative predictive value for frequent vomiting was $92.9 \%$. There was no significant difference for the other reflux indices (table 1).

Seven infants $(26.9 \%)$ were perceived to be irritable by their parents. Three of these infants had pathological GOR (positive predictive value $57.1 \%, \chi^{2}$ test $3 / 7 \vee 4 / 17, \mathrm{p}=0.06$ ). There was no significant difference in reflux indices (fractional reflux time, number of reflux episodes, and duration of reflux episodes) between infants who were irritable and those who were not (table 1). None of the infants in the study presented with haematemesis. Two infants had apnoeic episodes in the neonatal period, which were thought to be unrelated to reflux. Four infants $(15.4 \%)$ presented with frequent wheeze, only one of whom had pathological GOR.

FEEDING DETAILS AND GOR

Twenty of the $26(76.9 \%)$ infants were breast fed at the time of enrolment. Only two infants presented with feeding difficulties as perceived by the parents. There was no significant age difference between breast and bottle fed infants (2.0 $v 2.5$ months, $\mathrm{p}=0.38$ ). Reflux indices were not statistically different between the two groups (table 1 ).

\section{NUTRITIONAL ASSESSMENT AND CORRELATION} WITH GOR

At birth, z scores were normally distributed for weight for age (mean $0.15(0.20)$ ) and weight for length for age (mean $-0.29(0.20)$ ). Mean z scores at birth were not significantly different from zero (one sample $t$ test: $\mathrm{p}=0.46$ and $\mathrm{p}=$ 0.16 , respectively). At the time of $\mathrm{pH}$ monitoring, both $\mathrm{z}$ scores had fallen and were now significantly different from zero ( $\mathrm{z}$ weight for age $-1.00(0.20), \mathrm{p}=0.0001 ; \mathrm{z}$ weight for length for age $-0.68(0.18), p=0.001)$. On paired $t$ test there was a highly significant fall in $\mathrm{z}$ scores for weight for age $(p<0.0001)$, but not for weight for length for age $(p=0.22)$.

At the time of $\mathrm{pH}$ monitoring, eight infants $(30.8 \%)$ were failing to thrive as evidenced by either a $\mathrm{z}$ score for weight for age below 2 or a fall in $\mathrm{z}$ scores for weight for age or weight for length for age by more than 2 SD between birth and $\mathrm{pH}$ monitoring. For the eight patients with failure to thrive, $\mathrm{z}$ scores for weight for age $(-1.84(0.29) v-0.58(0.21) ; \mathrm{p}=0.0031)$ and weight for length for age $(-1.35(0.38) v-0.38$ $(0.18) ; p=0.032)$ were significantly lower than in the remaining 18 infants. There was no significant difference in reflux indices (number of episodes per 24 hours, duration of reflux episodes, and fractional reflux time) between infants with and without failure to thrive (table $1)$.

MECONIUM ILEUS AND ILEAL ATRESIA

Six infants $(23.1 \%)$ presented with intestinal obstruction at birth (five with meconium ileus, one with ileal atresia). The remaining 20 infants were found by routine neonatal screening at about 6 weeks of age. Although the infants who had presented with intestinal obstruction had slightly higher mean values for number of episodes per 24 hours and fractional reflux time, this did not reach statistical significance (table 1).

PANCREATIC STATUS AND GOR

Twenty two $(84.6 \%)$ of the infants had signs of pancreatic insufficiency at the time of $\mathrm{pH}$ monitoring and were started on enzyme supplements. Only four infants $(15.4 \%)$ had not developed steatorrhoea and were thriving well. Three of these had formal 72 hour faecal fat clearance measured, which was normal $(\geqslant 96 \%)$ in all three cases. Pancreatic status at the time of $\mathrm{pH}$ monitoring was not predictive of pathological reflux (table 1).

GENOTYPE AND GOR

Of the 26 infants, 16 (61.5\%) were homozygous for the common deletion $\Delta \mathrm{F}_{508}$. Seven infants $(26.9 \%)$ were compound heterozygous, and three $(11.1 \%)$ had other mutations. The genotypes are detailed in table 2 . All reflux indices were slightly more frequent in the group of homozygous infants. This reached statistical significance for the mean duration of reflux episodes. There was no significant difference for number of reflux episodes per 24 hours or the fractional reflux time (table 1).

\section{CHEST RADIOGRAPHS AND CORRELATION WITH} GOR

Of the 26 patients, $15(57.7 \%)$ had a normal chest $x$ ray at the time of $\mathrm{pH}$ monitoring, and $11(42.3 \%)$ had abnormal films. Of these, four had focal changes (consolidation or collapse) and seven had diffuse changes (hyperinflation and/or peribronchial thickening). Infants with normal $x$ rays were slightly younger than infants with radiological abnormalities, although this did not reach statistical significance $(1.8(0.12) v 2.4(0.45) ; \mathrm{p}=0.23$, NS). The infants with a normal chest $x$ ray had a significantly higher fractional reflux time than those with an abnormal $x$ ray (table 1). All infants with abnormal chest $x$ rays had a normal fractional reflux time $<10 \%\left(\chi^{2}\right.$ test, $\left.\mathrm{p}=0.03\right)$.

\section{Discussion}

The first clinical description of a high incidence of GOR in cystic fibrosis as evidenced by barium study was published by Feigelson and Sauvegrain in $1975 .{ }^{4}$ Since then several studies have been published on this topic. ${ }^{5-11} 16 \mathrm{Re}-$ ported incidence figures for GOR vary widely between $25 \%$ and $100 \% .^{46710}$ In our study, about one fifth of newly diagnosed infants with cystic fibrosis had pathological GOR. This 
incidence is considerably lower than in most studies. Vandenplas et al provided normal values for GOR in a large study of 509 healthy infants. ${ }^{18}$ They found that in the first 12 months of life a fractional reflux time of $10 \%$ was normal (95th centile), decreasing from about $13 \%$ at birth to $8 \%$ at 12 months. Using this study as a historical control, the risk of pathological GOR in cystic fibrosis was about four times the risk in healthy infants. Our study was conducted prospectively and is close to a population based study. The high incidence figures in other studies are most likely to be due to selection bias, enrolling mainly patients with symptomatic reflux. An alternative explanation is that the incidence of pathological reflux in cystic fibrosis may increase with age.

Frequent vomiting was associated with a significantly increased fractional reflux time, although the positive predictive value for frequent vomiting was only $33 \%$. In contrast, the high negative predictive value of $93 \%$ suggests that absence of frequent vomiting is a useful negative predictor of significant reflux. Similarly, in a recent study on GOR in otherwise healthy irritable infants, the absence of frequent vomiting was also found to be a useful negative predictor. ${ }^{21}$

Failure to thrive is a common presentation in cystic fibrosis and may be compounded by GOR and loss of nutrients. Compared with $\mathrm{z}$ scores at birth we found a significant fall in $\mathrm{z}$ scores for weight for age at the time of $\mathrm{pH}$ monitoring, which coincided with diagnosis and start of enzyme supplementation in many of the infants. Other authors have found evidence of growth retardation at the time of diagnosis in infants with cystic fibrosis found at neonatal screening. ${ }^{3}$ This emphasises the need for early diagnosis in order to start early nutritional supplementation. Eight infants (30.7\%) fulfilled our criteria for failure to thrive, with $\mathrm{z}$ scores 2 SD below the 50th centile for weight. There was no increased incidence of pathological reflux in these infants.

Sixteen infants were homozygous for $\Delta \mathrm{F}_{508}$, and seven were compound heterozygotes. There was no difference in clinical presentation between the two groups. Except for four $(15.4 \%)$, all infants had developed pancreatic insufficiency at the time of $\mathrm{pH}$ monitoring. This is in keeping with a recent multicentre study that found similar rates of pancreatic insufficiency in infants with cystic fibrosis who were homozygous or compound heterozygous for $\Delta \mathrm{F}_{508}{ }^{22}$ The mean duration of reflux episodes was significantly longer for infants who were $\Delta \mathrm{F}_{508}$ homozygous. This may indicate delayed oesophageal clearance in these patients. The significance of this finding, however, is uncertain and interpretation is hampered by small numbers, although phenotypic variations have been reported among different cystic fibrosis genotypes. There was no statistical difference in the remaining reflux indices for genotype or pancreatic status.

Six $(23 \%)$ of the study infants presented with meconium ileus or ileal atresia. This is comparable with the incidence rate of $21 \%$ found for the cystic fibrosis cohort in the state of Victoria between 1973 and $1992 . .^{23}$ Infants with meconium ileus have a high morbidity secondary to abdominal surgery, often requiring prolonged hospital admission. They often need parenteral nutrition and are at particular risk of failure to thrive. Despite these concerns we did not find an increased incidence of pathological reflux in the six infants that presented with intestinal obstruction.

The mechanism of GOR in cystic fibrosis is not clear. Some investigators initially suggested that reflux may occur secondary to lung disease. They proposed that hyperinflation and stenting of the diaphragm caused widening of the angle of His and impairment of gastrooesophageal competence. ${ }^{416}$ In our study, we found no correlation between severity of lung disease and severity of GOR. All infants with significant reflux had normal chest $x$ rays, and pathological reflux appears to be present before lung disease is established.

Cucchiara et al showed that most reflux episodes in cystic fibrosis occurred during transient lower oesophageal sphincter relaxations and were not due to impaired lower oesophageal sphincter tone. ${ }^{94}$ Transient sphincter relaxations are increased during distension of the gastric fundus, and hyperalimentation of cystic fibrosis infants may be a predisposing factor. Delayed gastric emptying has been recognised as a risk factor for pathologically increased GOR. The information on gastric emptying in cystic fibrosis is not conclusive. Gastric emptying of liquids was initially thought to be delayed in cystic fibrosis. ${ }^{25}$ Two more recent studies found that gastric emptying of non-homogenised fat ${ }^{26}$ and of solids ${ }^{27}$ is faster in patients with cystic fibrosis than in normal individuals. Breast fed infants may have lower rates of GOR and more rapid gastric emptying than bottle fed infants. ${ }^{28}$ Although most infants in our study were breast fed, we did not find a difference in reflux indices compared with the bottle fed infants. The presence of pancreatic enzyme supplements may alter gastric emptying. However, infants receiving pancreatic enzyme supplements had no significant differences in GOR compared with infants not on enzyme replacement.

Besides its peptic complications, GOR may adversely affect pulmonary function and worsen early failure to thrive. Postural drainage chest physiotherapy is commonly prescribed in these infants and increases the risk of GOR. ${ }^{15}$ Absence of frequent vomiting was the only useful negative predictor for pathological GOR. We found no significant association for irritability, meconium ileus, pancreatic status, breast feeding, failure to thrive, genotype, and chest $x$ ray findings. In the absence of clear clinical predictors, clinicians need a high degree of suspicion to make a diagnosis of pathological GOR in young infants with cystic fibrosis. The role of GOR as a contributor to development of lung disease clearly needs further study. We gratefully acknowledge the expert assistance of Dianne
Simpson, gastroenterology nurse, with oesophageal $\mathrm{pH}$ moniSimpson, gastroenterology nurse, with oesophageal $\mathrm{pH}$ moni-
toring. Financial support was provided by a grant from the toring. Financial support was provided by a g
Royal Children's Hospital Research Foundation. 
1 FitzSimmons SC. The changing epidemiology of cystic fibrosis. F Pediatr 1993;122:1-9.

PE. Dried-blood spot screening for cystic fibrosis in the newborn. Lancet 1979;i:472-4.

3 Dankert-Roelse JE, te Meerman GJ. Long term prognosis of patients with cystic fibrosis in relation to early detection by neonatal screening and treatment in a cystic fibrosis centre. Thorax 1995;50:712-8.

4 Feigelson J, Sauvegrain J. Réflux gastro-oesophagien dans la mucoviscidose. Nouv Presse Med 1975;4:2729-30.

5 Vinocur CD, Marmon L, Schidlow DV, et al. Gastroesophageal reflux in the infant with cystic fibrosis. Am $\mathcal{7}$ Surg 1985;149:182-6.

6 Scott RB, O'Loughlin EV, Gall DG. Gastroesophageal reflux in patients with cystic fibrosis. F Pediatr 1985;106: 223-7.

7 Dab I, Malfroot A. Gastroesophageal reflux: a primary defect in cystic fibrosis? Scand $\mathcal{f}$ Gastroenterol Suppl 1988;143:125-31

8 Gustafsson PM, Fransson SG, Kjellman NI, et al. Gastro-oesophageal reflux and severity of pulmonary Gastro-oesophageal reflux and severity of pulmonary 449-56.

9 Cucchiara S, Santamaria F, Andreotti MR, et al. Mechanisms of gastro-oesophageal reflux in cystic fibrosis. Arch Dis Child 1991;66:617-22.

10 Malfroot A, Dab I. New insights on gastro-oesophageal reflux in cystic fibrosis by longitudinal follow up. Arch $\mathrm{D} i$ Child 1991;66:1339-45.

11 Feigelson J, Girault F, Pecau Y. Gastro-oesophageal reflux and esophagitis in cystic fibrosis. Acta Paediatr Scand 1987; 76:989-90.

12 Bendig DW, Seilheimer DK, Wagner ML, et al. Complications of gastroesophageal reflux in patients with cystic fibrosis. F Pediatr 1982;100:536-40.

13 Hassall E, Israel DM, Davidson AG, et al. Barrett's esophagus in children with cystic fibrosis: not a coincidental gus in children with cystic fibrosis: not a coin

14 Chow WH, Finkle WD, McLaughlin JK, et al. The relation of gastroesophageal reflux disease and its treatment to of gastroesophageal reflux disease and its treatment to
adenocarcinomas of the esophagus and gastric cardia. adenocarcinomas of the

15 Button BM, Heine RG, Catto-Smith AG, et al. Postural drainage and gastro-oesophageal reflux in infants with cystic fibrosis. Arch Dis Child 1997;76:148-50.
16 Stringer DA, Sprigg A, Juodis E, et al. The association of cystic fibrosis, gastroesophageal reflux, and reduced

17 Andze GO, Brandt ML, St Vil D, et al. Diagnosis and treatment of gastroesophageal reflux in 500 children with respiratory symptoms: the value of $\mathrm{pH}$ monitoring. 7 Pediatr Surg 1991;26:295-9.

18 Vandenplas Y, Goyvaerts H, Helven R, et al. Gastroesophageal reflux, as measured by 24 -hour $\mathrm{pH}$ monitoring, in 509 healthy infants screened for risk of sudden infant death syndrome. Pediatrics 1991;88:834-40.

19 Stern RC. The diagnosis of cystic fibrosis. $N$ Engl f Med 1997;336:487-91.

20 Strobel CT, Byrne WJ, Ament ME, et al. Correlation of esophageal length in children with height: application to the Tuttle test without prior esophageal manometry. F Pediatr 1979;94:81-4.

21 Heine RG, Jaquiery A, Lubitz L, et al. Role of gastrooesophageal reflux in infant irritability. Arch Dis Child 1995;73:121-5.

22 Hamosh A, Corey M, The Cystic Fibrosis GenotypePhenotype Consortium. Correlation between genotype and phenotype in patients with cystic fibrosis. $N$ Engl f Med 1993;329:1308-13.

23 Sawyer SM, Taylor R, MacMahon R, et al. Meconium ileus in cystic fibrosis. Pediatr Surg Int 1994;9:180-4.

24 Dent J, Dodds WJ, Friedman RH, et al. Mechanism of gastroesophageal reflux in recumbent asymptomatic human subjects. Gastroenterology 1980;65:256-67.

25 Smith HL, Hollins GW, Booth IW, et al. Gastric emptying of liquids in cystic fibrosis. Acta Universitatis Carolinae Med 1990;36:161-4

26 Carney BI, Jones KL, Horowitz M, et al. Gastric emptying of oil and aqueous meal components in pancreatic insufficiency: effects of posture and on appetite. $A m \mathcal{F}$ Physiol 1995;268:G925-32.

27 Collins CE, Francis JL, Thomas P, et al. Gastric emptying time is faster in cystic fibrosis. I Pediatr Gastroenterol Nutr (in press).

28 Heacock HJ, Jeffery HE, Baker JL, et al. Influence of breast versus formula milk on physiological gastroesophageal reflux in healthy, newborn infants. $\mathcal{F}$ Pediatr Gastroenterol Nutr 1992;14:41-6. 